\title{
The creep compaction behavior of crushed mudstones under the step loading in underground mining
}

\author{
Zhibiao Guo ${ }^{1,2} \cdot$ Qiong Wang $^{2}$ (1) Songyang Yin $^{2} \cdot$ Xiaohui Kuai $^{2} \cdot$ \\ Dongshan $\mathrm{Yan}^{2} \cdot \mathrm{Mengyi} \mathrm{Li}^{2} \cdot$ Yandong $\mathrm{Qu}^{2}$
}

Received: 21 November 2018/Revised: 6 February 2019/Accepted: 27 February 2019/Published online: 8 March 2019

(C) The Author(s) 2019

\begin{abstract}
The crushed rocks are used as a filling material in mined-out areas of underground mining. Compared with the man-made filling materials, the crushed rocks exhibit higher compressibility and lower stability, which may result in instability of surrounding rock and surface subsidence. To study the creep compaction behavior of crushed mudstones, a series of creep tests are conducted. The investigations show that the creep compaction behavior of crushed mudstones is highly dependent on the original grain composition and axial stress applied on the samples. The samples with more large particles are easier to deform at initial loading stage for more large voids existed in the samples, and exhibit greater stability than those with smaller particles when the axial stress less than the bearing capacity of "framework structure". When the axial stress is higher than $20 \mathrm{MPa}$, the influences of grain composition on deformability of crushed mudstones are weakened after the samples experience repeated compression. At lower stress level, the creep behavior prefers to occur in the samples with smaller particles, which is mainly caused by particles flow without significant particle breakage. As the axial stress increases, the single-sized sample with smaller particle size and the well-graded sample with larger Talbol power exponent $n$ present more unstable under the constant stress. In addition, the filling of the residual intergranular voids by small particles formed by crushing and splitting behavior is the main cause of creep deformation. Lastly, a creep equation of crushed mudstones is obtained in this paper, which can agree with the experimental results in good.
\end{abstract}

Keywords Crushed mudstones · Grain composition · Creep compaction behavior · Underground mining

\section{Introduction}

In recent years, an innovative non-pillar mining approach by fracturing roof to maintain entry (FRME) (He et al. 2015) is widely used in many coal mines in china (Guo et al. 2016; He et al. 2017; Wang et al. 2018) due to its high recovery rate and low accident rate. In FRME approach, one of the key technologies is the directional fracturing in

Qiong Wang

wq1989@126.com

$1 \quad$ State Key Laboratory for Geomechanics and Deep Underground Engineering, China University of Mining and Technology, Beijing 100083, China

2 School of Mechanics and Civil Engineering, China University of Mining and Technology, Beijing 100083, China the gob side roof, which cuts off the transfer of overburden pressure to entry roof, and falls the gob roof down. The crushed rocks formed by the gob roof caving are used to naturally fill the gob, the man-made filling materials are not needed. As the working face continues to advance, the crushed rocks in mined-out areas are gradually compacted and provide the most important structural elements to support the overburden strata, as shown in Fig. 1 [the rib made up of crushed rocks is called as gangue rib (Guo et al. 2018)]. But compared with the man-made filling materials, the crushed rocks exhibit higher compressibility and low stability under the pressure of overburden strata, which may result in instability of surrounding rock and surface subsidence. Therefore, the creep compaction behavior of crushed rocks should be taken seriously in underground mining for the FRME approach. 


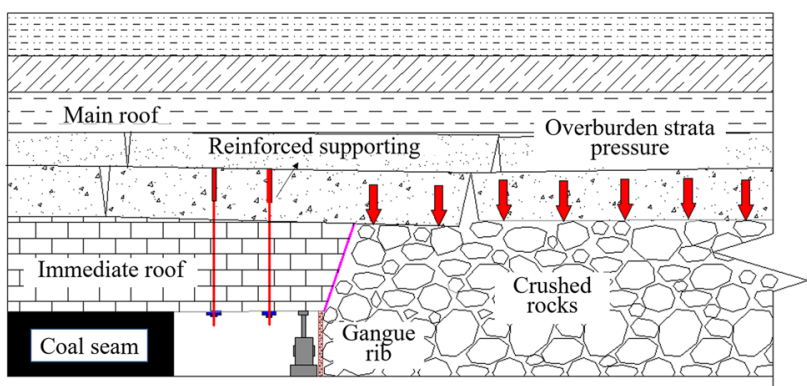

Fig. 1 Schematic diagram of surface subsidence in FRME approach

Many researches are conducted on the creep compaction behavior of rocks (Scholz 1968; Hagin and Zoback 2004); Lade and Liu (1998) conduct triaxial test on saturated silt and state that the creep deformation and plastic strain of saturated silt are the same in nature under drainage condition; The study by Hagin and Zoback (2004) on physical mechanism of dry unconsolidated sands under different constant stress conditions shows that the creep strain results from grain rearrangement; Karner et al. (2005) presents laboratory experiments on saturated quartz and concludes that the deformation under low stresses is mainly caused by granular flow without significant grain breakage and that under high stresses results from granulation and catacaustic flow; He et al. (2003) conducts theoretical and experimental study on creep compaction of quartz and concludes that creep compaction rate is control by pore-fluid flow rates. Liang et al. (2003) conducts creep compaction test on rockfill and shows that the main factor causing the creep deformation of rockfill is that the smaller breakage rockfill moves into the pores under the constant stress; Hu et al. (2014) measures the creep deformation law of slope largergrained soil under different stress level; However, the most researches on the creep compaction behavior are concentrated on different types of intact rocks (Fujii et al. 1999; Yang et al. 1999; Berest et al. 2005; Heap et al. 2009a, b) and the crushed rock aggregates used as road base (Suiker et al. 2005; Wichtmann et al. 2009; Thakur et al. 2013; Sun et al. 2015), the creep behavior of crushed rocks in underground mining conditions is only investigated by $\mathrm{Ma}$ et al. (2014). In the authors' works, the creep behavior of saturated disaggregated sandstones is studied and an abrupt change in axial displacement is observed in some samples.

In this work, the creep compaction tests are carried out on crushed mudstones with different grain compositions. The influences of grain composition on creep compaction behavior are investigated under the step loading. The test results show that the creep compaction behavior of crushed mudstones is highly dependent on the original grain composition and axial stress applied on the samples. In particular, the large particles in samples have significant influence on the creep compaction behavior. In addition, the deformation mechanism of crushed rocks is discussed in this paper, which indicates that the compressive deformation of crushed rocks is closely related with particles rearrangement (voids compression), particles crushing and splitting.

\section{Experimental investigation}

\subsection{Specimen preparation}

The crushed mudstones are collected from the mined-out areas of Zhaogu No. 1 coal mine in China. The uniaxial compressive strength of intact mudstone is $19.8 \mathrm{MPa}$, and the natural density is $2.65 \mathrm{~g} / \mathrm{cm}^{3}$. On the basis of size effect, the ratio of the inner diameter of the compacting device to the maximum particle size in the crushed rock sample should be less than 5 . In the creep compaction tests, six sets of crushed mudstone samples with different grain compositions are prepared. The grain composition of all the samples is shown in Fig. 2 and the particle distribution of the samples is presented in Table 1. Both single-sized samples (S-1, S-2, S-3) and well-graded samples (S-4, S-5, S-6) are considered in the test. The particle mass in different sizes of the well-graded samples depends on:

$\frac{M_{\mathrm{d}}}{M_{t}}=\left(\frac{d}{D}\right)^{n} \times 100 \%$

where $d$ is the particle size of crushed mudstones, $\mathrm{mm} ; D$ is the maximum particle size in crushed rock sample, $\mathrm{mm} ; M_{\mathrm{d}}$ is the mass of the crushed rocks with a particle size less than or equal to $d, \mathrm{~g} ; M_{\mathrm{t}}$ is the total mass of crushed mudstone sample, $\mathrm{g} ; n$ is the Talbol power exponent, the proportion of larger particles is increased by Talbol power exponent actually.

\subsection{Experimental apparatus}

The creep compaction behavior of crushed mudstones is studied by a five-axis triaxial creep tester. The tester can carry out creep experiments with five samples at the same time, which dramatically shorten the creep test time. The structure diagram of the creep tester is shown in Fig. 3. Its maximum axial loading is $600 \mathrm{kN}$ and maximum axial deformation is $200 \mathrm{~mm}$. In addition, it can work continuously for more than $1000 \mathrm{~h}$.

The crushed mudstone samples are placed in the compacting device with the thickness of $16 \mathrm{~mm}$. Fully quenched 45\# steel is used to improve the hardness and strength of the compacting device. Its detailed structure and dimension are shown in Fig. 3. 


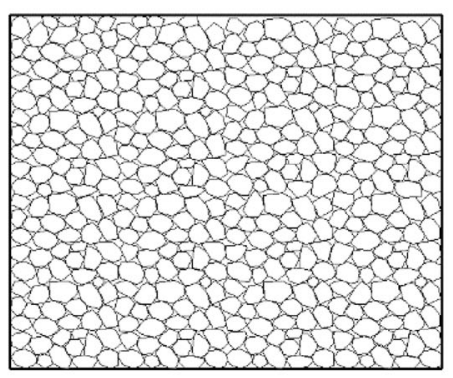

(a) S-1

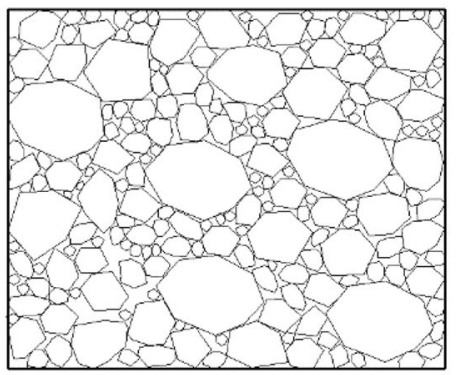

(d) S-4

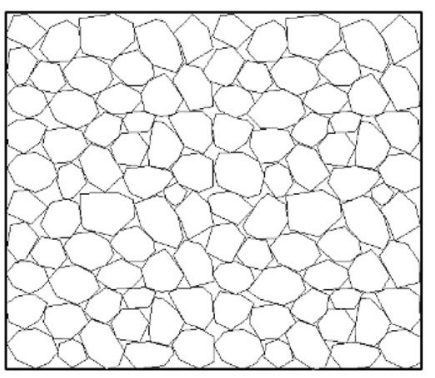

(b) $\mathrm{S}-2$

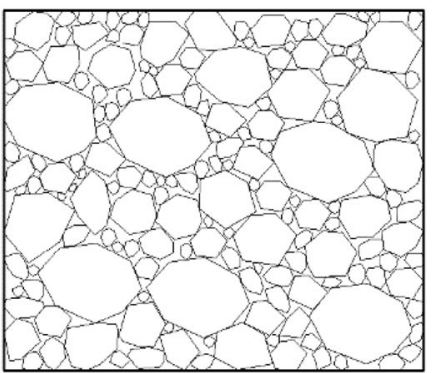

(e) $\mathrm{S}-5$

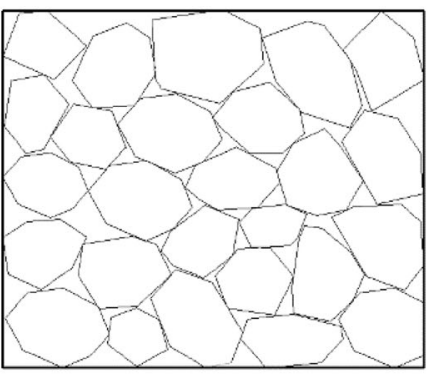

(c) S-3

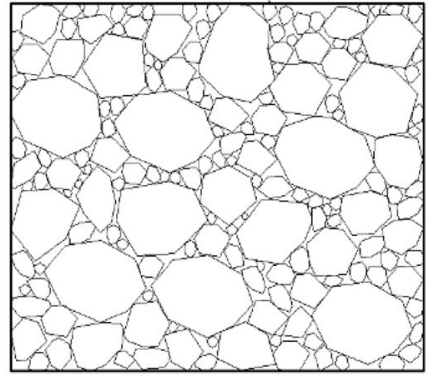

(f) $\mathrm{S}-6$

Fig. 2 Grain composition diagram of crushed mudstone samples

Table 1 Particle distribution of crushed mudstone samples

\begin{tabular}{lllllll}
\hline Lithology & Symbol & Talbol power exponent & \multicolumn{2}{c}{ Initial particle distribution (\%) } & \multicolumn{2}{c}{ Mass of sample (g) } \\
\cline { 5 - 7 } & & & $2-5 \mathrm{~mm}$ & $5-10 \mathrm{~mm}$ & $10-20 \mathrm{~mm}$ \\
\hline Mudstone & S-1 & - & 100 & 0 & 0 & 763.2 \\
& S-2 & - & 0 & 100 & 0 & 777.4 \\
& S-3 & - & 0 & 0 & 300 & 792.2 \\
& S-4 & 0.2 & 34.4 & 30.5 & 35.1 & 820.8 \\
& S-5 & 0.4 & 29.3 & 30.5 & 40.2 & 840.0 \\
& S-6 & 0.6 & 24.6 & 30 & 45.4 & 845.0 \\
\hline
\end{tabular}
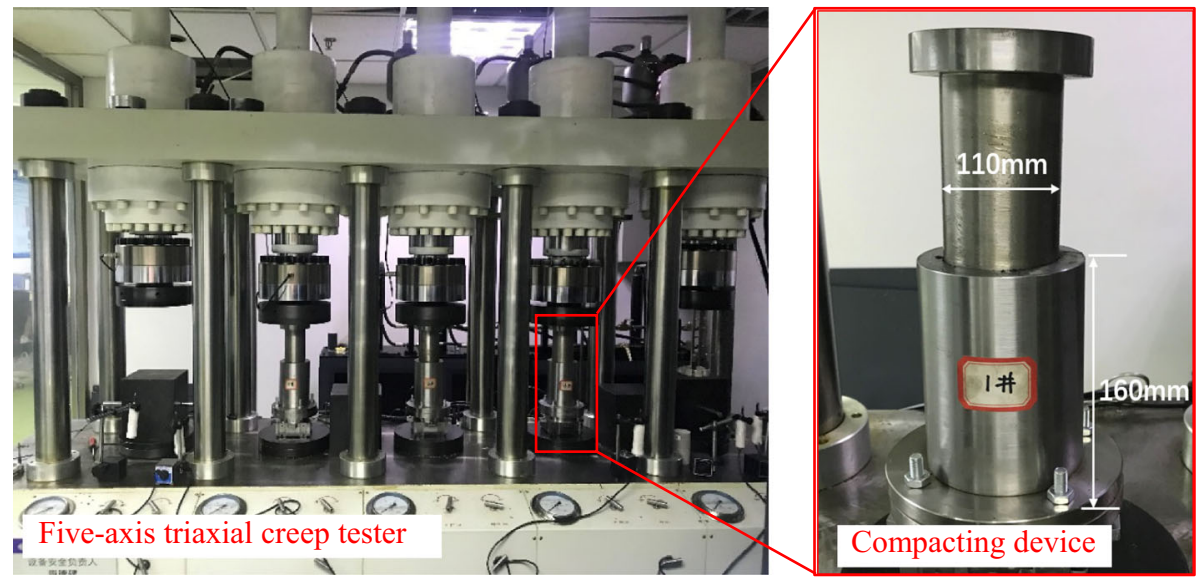

Fig. 3 Creep test system of crushed mudstones 


\subsection{Experimental methods}

\subsubsection{Experimental procedure}

(1) The crushed mudstones are placed into a thin plastic cylinder with the same diameter as the compaction device;

(2) The crushed mudstones in the plastic cylinder are compacted slightly to achieve the target height of $150 \mathrm{~mm}$, ensuring that the crushed mudstones are well-mixed and even-distributed;

(3) Recording the mass of rock samples and pouring the crushed rocks from plastic cylinder into the compaction device;

(4) The initial height of crushed mudstones should be $150 \mathrm{~mm}$ before loading. If it is higher than $150 \mathrm{~mm}$, the rubber hammer is used to gently tap the pressure plug to achieve the target height.

\subsubsection{Loading mode}

The stress state of the crushed rocks in mined-out area is closely related to the caving height of the overburden strata. As the working face advances, the pressure acting on the crushed rocks increases with caving height. It can be considered that the pressure under crushed rocks is increasing as a trapezoidal growth trend on the assumption that the pressure acting on the crushed rocks between two roof separation activities is kept constant. In order to simulate the stress state in underground mining, the step loading method is used in the creep tests. The step loading has four levels, which are 10, 15, 20, $25 \mathrm{MPa}$ respectively. Each loading stage is kept for $72 \mathrm{~h}$. The loading path is shown in Fig. 4. During the loading process the loading

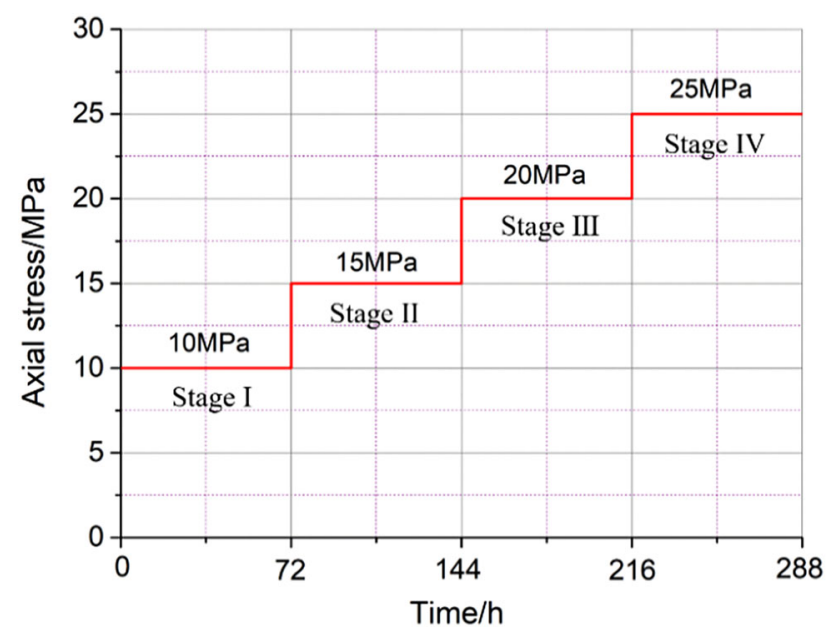

Fig. 4 The loading path of creep test rate is set as $0.5 \mathrm{MPa} / \mathrm{s}$, and the load remains constant after the predetermined axial load is reached.

\section{Experimental results}

\subsection{The compaction characteristics of different graded crushed mudstones}

Figure 5 shows the curves of the relationship between axial displacement and time of crushed mudstones in creep tests. In addition, the axial displacement corresponding to each loading stage is shown in Table 2. From the Fig. 5 and Table 2, we can know that the final axial displacements of S-1, S-2 and S-3 are 52.4, 53.0, $55.5 \mathrm{~mm}$ respectively, which indicates that the final axial displacement increases as the particle size increases for single-sized samples. For well-graded samples, the final axial displacements of $\mathrm{S}-4$, S-5, S-6 are 50.9, 48.8, $45.7 \mathrm{~mm}$, which present a decreasing trend with the increased Talbol power exponent n. Obviously, the deformability of the samples with wellgraded particles is lower than those with single-sized particles.

Under the step loading conditions, the axial stress-displacement curves of crushed mudstones are shown in Fig. 6. For samples S-1, S-2, S-4, S-5, the axial displacements corresponding to each loading stage decrease progressively as the axial loading increases. Taking S-1 as an example, the increments of axial displacement for stage I, stage II, stage III and stage IV are 28.4, 13.0, 6.8 and $4.2 \mathrm{~mm}$, which show a significant decreasing trend. However, the heterogeneous decreases of S-3, S-6 at stress level of 10 to $15 \mathrm{MPa}$ are observed, which are marked in Fig. 5c, f. The possible mechanism of the heterogeneous decrease in axial displacement is the higher compressive strength of "framework structure" formed by large particles in crushed rock samples, which is discussed in Sect. 4.

As shown in Table 2 that the ratios of axial displacement of stage I to total axial displacement for all crushed rock samples are in the range of $54.2 \%-74.9 \%$, which are maximal at all loading stages. In the stage I, the compression of the large void volume existed in crushed rock samples is the main reason for the axial displacement. Meanwhile, it can be observed that the axial displacement increases with the increased particle size or Talbol power exponent $\mathrm{n}$ at this stage, that is because the samples with larger particle size or larger $n$ possess more larger void volume than samples with smaller particles. When the axial stress is higher (15 MPa), most of the large voids in samples are compressed after first loading stage, and a "framework structure" is formed in samples with large particles (S-3, S-6), which improves the compression strength of crushed rocks and makes the deformability of 


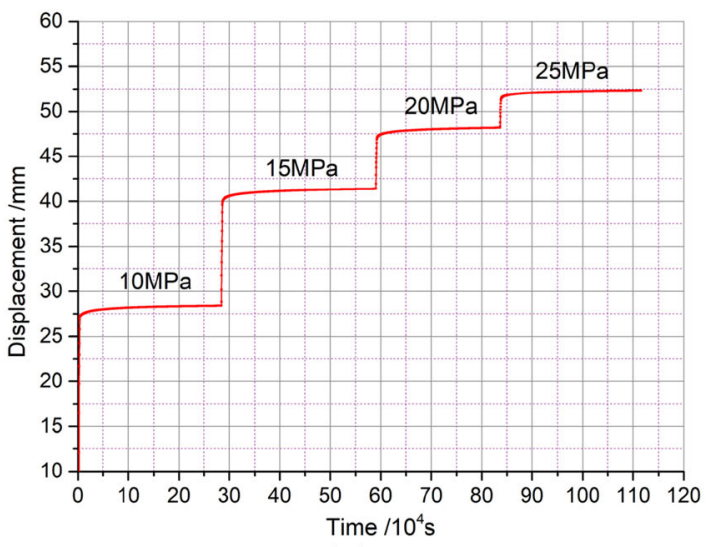

(a) $\mathrm{S}-1$

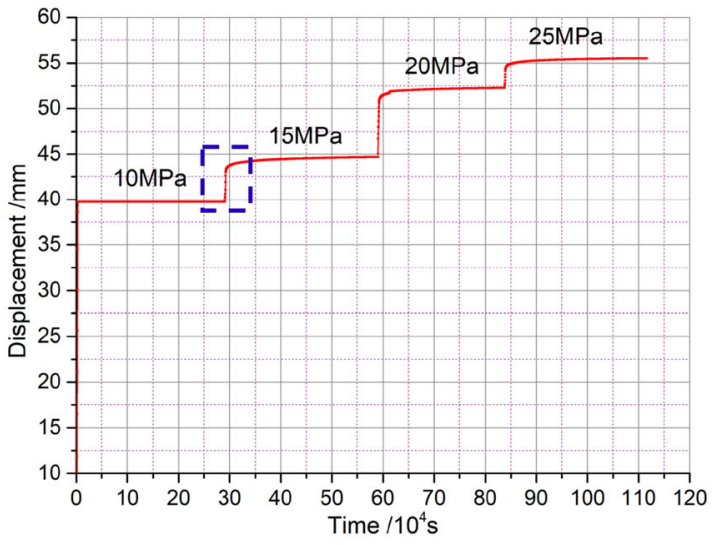

(c) $\mathrm{S}-3$

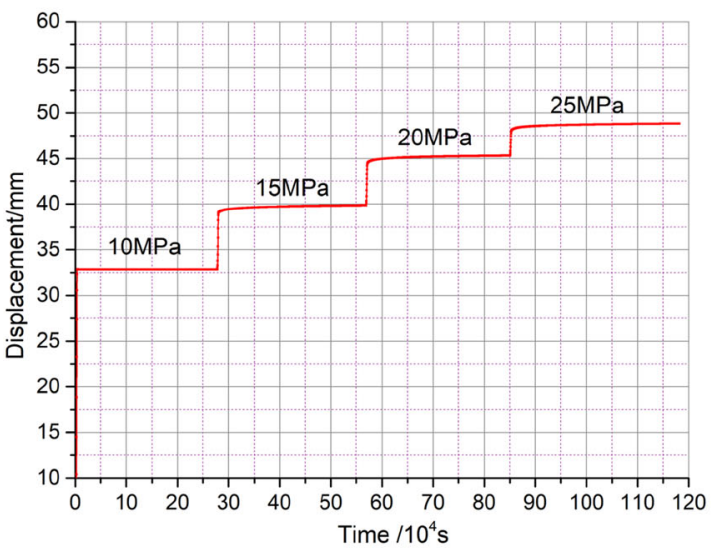

(e) $\mathrm{S}-5$

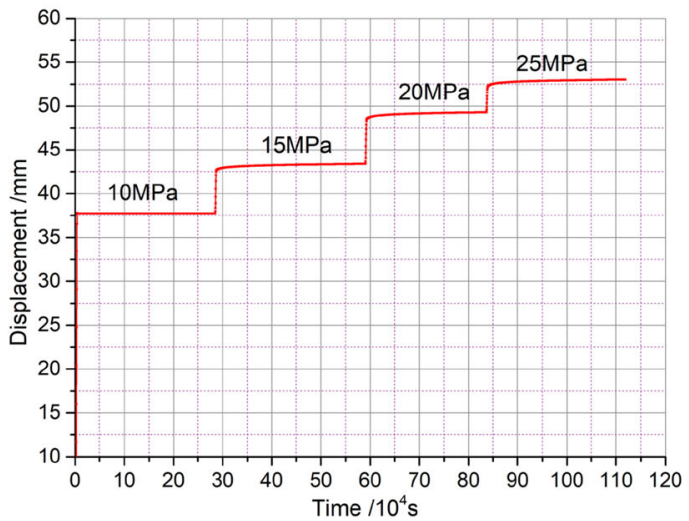

(b) S-2

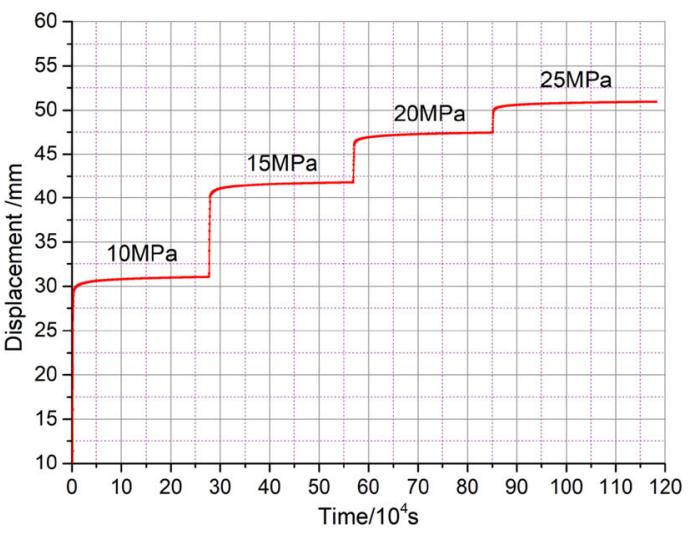

(d) S-4

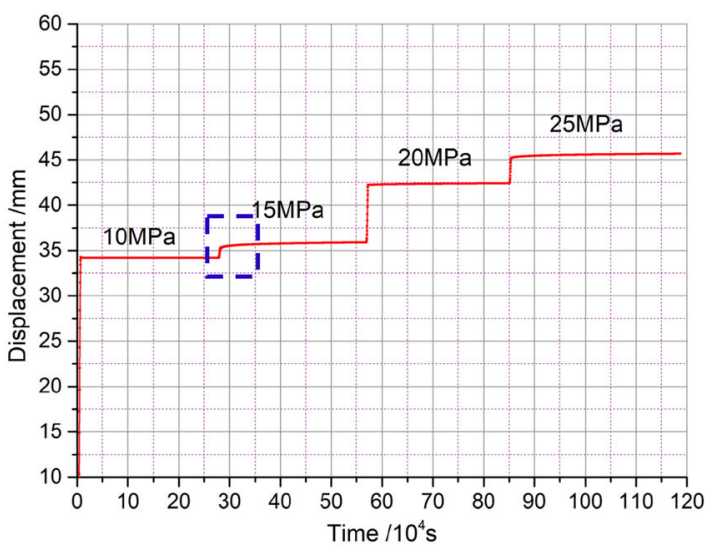

(f) S-6

Fig. 5 The time-displacement curves of crushed mudstones with different grain composition

samples with larger particles is lower than those with smaller particles. When the axial stress is higher than $20 \mathrm{MPa}$, the structures of crushed rock are compacted, the axial displacement for all crushed rock samples are nearly equal.

The void ratio-axial stress $(e-p)$ curves of crushed mudstones with different grain compositions are shown in Fig. 7. The compression coefficience is used to value the deformability of crushed rocks, which is defined as the relative decrease of the void ration with increasing pressure in compaction test. It is calculated by

$a_{i}=\frac{\Delta e_{i}}{\Delta p_{i}}=\frac{e_{i 1}-e_{i 2}}{p_{i 2}-p_{i 1}} \quad(i=\mathrm{I}, \mathrm{II}, \mathrm{III}, \mathrm{IV})$

where $\triangle e_{i}$ is the decrement of void ratio at $i$ th loading stage; $\triangle p_{i}$ is the increment of pressure at $i$ th loading stage; 
Table 2 The axial displacement of crushed mudstones at each loading stage

\begin{tabular}{|c|c|c|c|c|c|}
\hline \multirow[t]{2}{*}{ Symbol } & \multirow[t]{2}{*}{ Final displacement $(\mathrm{mm})$} & \multicolumn{4}{|c|}{ The value (percentage) of axial displacement in each loading stage $(\mathrm{mm})$} \\
\hline & & $10 \mathrm{MPa}$ & $15 \mathrm{MPa}$ & $20 \mathrm{MPa}$ & $25 \mathrm{MPa}$ \\
\hline S-1 & 52.4 & $28.4(54.2 \%)$ & $13.0(24.8 \%)$ & $6.81(13.0 \%)$ & $4.2(8.0 \%)$ \\
\hline S-2 & 53.0 & $37.3(70.4 \%)$ & $6.1(11.5 \%)$ & $5.9(11.1 \%)$ & $3.7(7.0 \%)$ \\
\hline S-3 & 55.5 & $39.7(71.5 \%)$ & $5.0(9.0 \%)$ & $7.6(13.7 \%)$ & $3.2(5.8 \%)$ \\
\hline S-4 & 50.9 & $31.1(61.1 \%)$ & $10.7(21.0 \%)$ & $5.7(11.2 \%)$ & $3.4(6.7 \%)$ \\
\hline S-5 & 48.8 & $32.9(67.4 \%)$ & $7.1(14.5 \%)$ & $5.5(11.3 \%)$ & $3.3(6.8 \%)$ \\
\hline S-6 & 45.7 & $34.2(74.9 \%)$ & $1.8(3.9 \%)$ & $6.5(14.2 \%)$ & $3.2(7.0 \%)$ \\
\hline
\end{tabular}

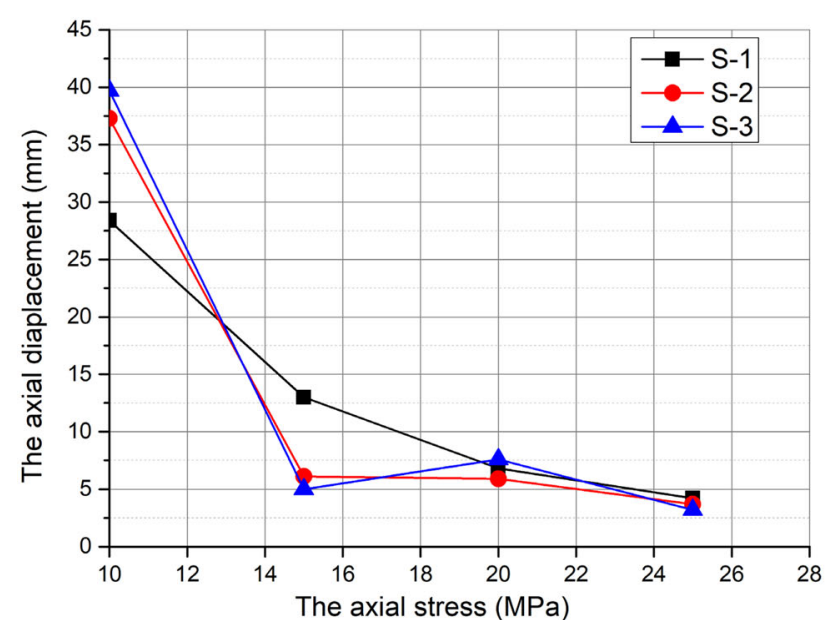

(a) poorly-graded

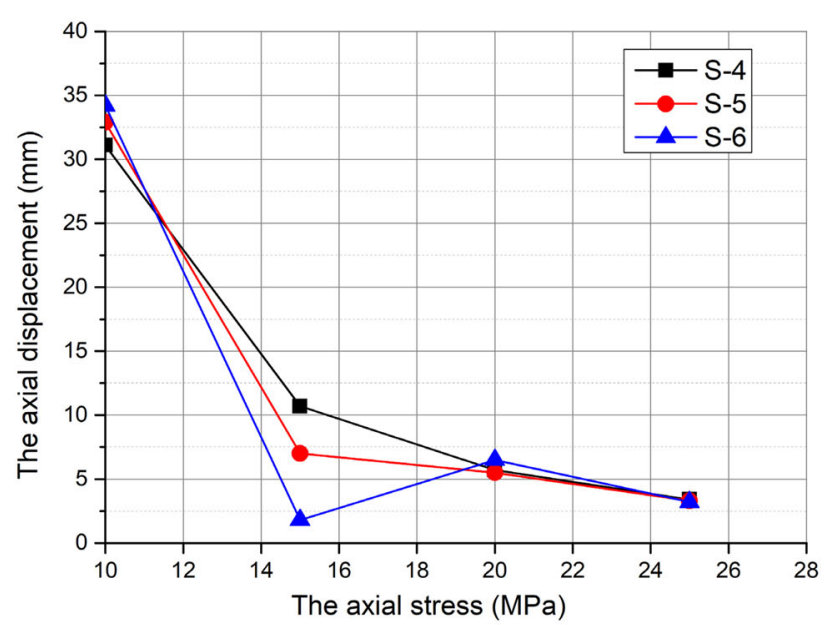

(b) well-graded

Fig. 6 The axial stress-displacement curves of crushed mudstones under step loading

$e_{i 1}$ is the void ratio before loading at $i$ th loading stage; $e_{i 2}$ is the void ratio after loading at $i$ th loading stage; $p_{i 1}$ is the initial pressure of $i$ th loading stage; $p_{i 2}$ is the final pressure of $i$ th loading stage.

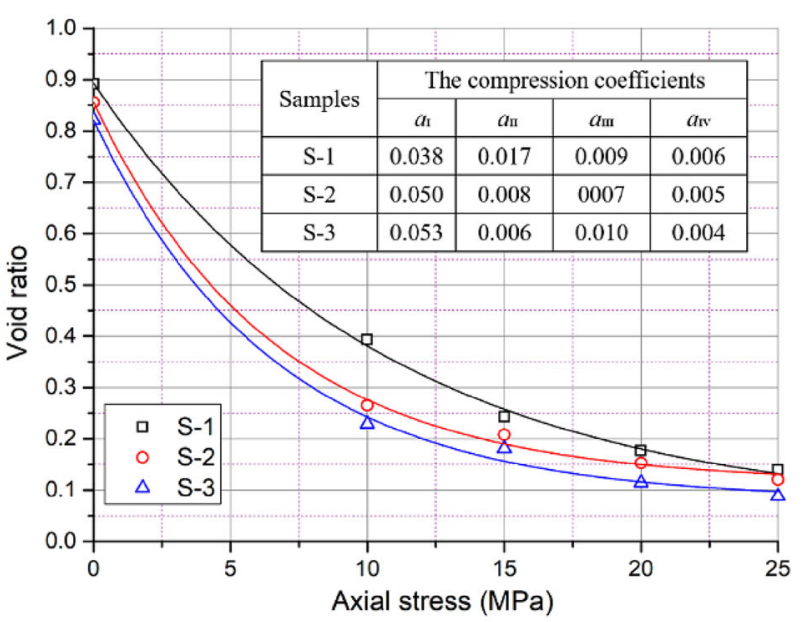

(a) poorly-graded

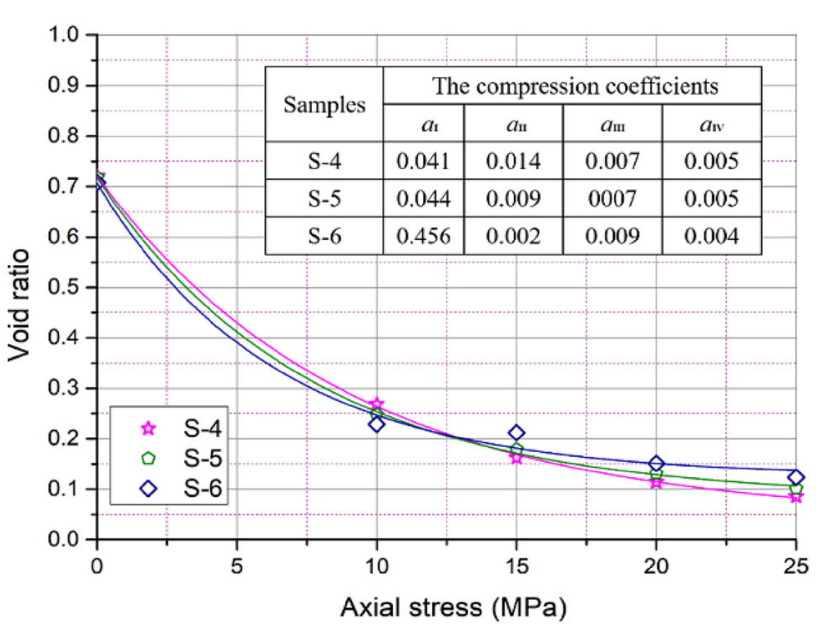

(b) well-graded

Fig. 7 The axial stress-void ratio curves of crushed mudstones with different grain composition

Based on Eq. (2), we can know that the larger the compression coefficient is, the higher the deformability of crush rocks is. The compression coefficients of different samples in each loading stage are presented in Fig. 7 as well. As it can be seen from Fig. 7 that when the axial 
stress is $10 \mathrm{MPa}$, the compression coefficient of the crushed rock samples is between 0.038 and $0.053 \mathrm{MPa}^{-1}$. With the axial stress increases, the compression coefficient decreases. When the axial stress reaches to $20 \mathrm{MPa}$, the compression coefficients is between 0.007 and $0.010 \mathrm{MPa}^{-1}$, which changes very slightly. And when the axial stress is $25 \mathrm{MPa}$, the compression coefficients tend to be stable, the values are in the range of 0.004-0.006 $\mathrm{MPa}^{-1}$. The change rule of the compression coefficients indicates that the ability to resist axial deformation of the crushed rock is improved as the axial stress increases. Based the test results, we can know that the samples with larger particles are easier to deform at initial period of roof caving and exhibit greater stability than smaller particles when the roof pressure less than the bearing capacity of "framework structure". However, when the axial stress reaches a certain value, the influences of grain composition on deformability of crushed mudstones are weakened after the crushed rock experiences repeated compression. The same variation law is observed in well-graded graded samples. Overall, the large particles in samples has a significant influence as the reinforcing effect on the compaction behavior of crushed mudstones no matter single-sized and welled-graded samples. But if the axial stress is sufficiently high, the influence of grain composition to the compressive strength of crushed rock is not distinct. The results also imply that the grain composition has a greater effect on the single-sized samples than the well-graded samples.

\subsection{The creep characteristics of different graded crushed mudstones}

The creep curve of crushed mudstones can be divided into three stages, as shown as Fig. 8. The first stage ( $A B$ section) is transient compression stage, in this stage, the axial displacement is quite large. The second stage ( $B C$ section)

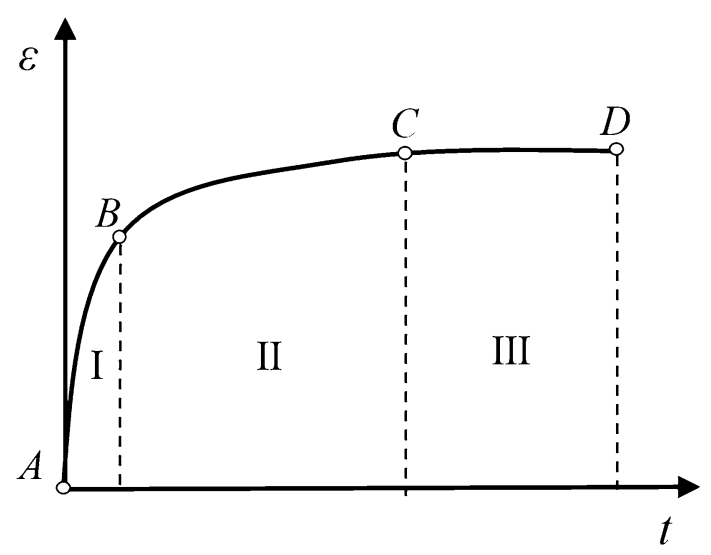

Fig. 8 Creep curve of crushed rocks is the deceleration stage and the creep rate decreases as time increases. The third stage ( $C D$ section) is the steady creep stage and the creep rate remains constant. The axial displacement in decay creep stage is somewhat small compared with the axial displacement in transient compression stage.

The creep displacement-time curves of crushed mudstones under the different axial stress are obtained by Boltmann superposition principle, as they show in Fig. 9. In Fig. 9, the points of different colors are the records of the test data and creep curves are partially enlarged. It can be seen from Fig. 9 that when the axial stress is $10 \mathrm{MPa}$, only S-1 and S-4 have creep behavior. With the axial stress increases to $15 \mathrm{MPa}$, the creep behavior occurs in all of the crushed mudstone samples. And when the axial stress reaches to 20 and $25 \mathrm{MPa}$, the creep behavior is not obvious in the well-graded sample S-6. For the stress level of $15,20,25 \mathrm{MPa}$, we can see that the creep displacement increases with the particle size at the same stress level for single-sized samples. For the well-graded samples, the creep displacement decreases as the Talbol power exponent $n$ increases. The test results imply that the creep behavior is not inclined to occur in the samples with larger particles under the lower stress level. In a word, more large particles filled in the mined-out areas is beneficial to the long-turn stability of gangue rib in FRME approach when the roof pressure is lower. But as the roof pressure increases, the single-sized sample with smaller particle size and the wellgraded sample with larger Talbol power exponent $n$ present more stable under the constant roof pressure conditions.

An abrupt change of $\mathrm{S}-3$ is observed under the axial stresses of $20 \mathrm{MPa}$, which is in correspondence with the investigations by Ma et al. (2014). Compared with the test results of $\mathrm{Ma}$, the occurrence rate of abrupt change in this test is lower apparently, which provides further evidence that the existence of water in underground mining has positive influence on stress corrosion in the samples.

From the creep test results in Fig. 9, the relationship between the axial displacement and time of the crushed mudstones can be described by

$\varepsilon=a-b e^{(-t-c) / d}$

where $\varepsilon$ is the axial displacement of crushed mudstones; $t$ is the loading time; $a, b, c, d$ are fitting parameters of the crushed mudstone samples, which are affected by grain composition and the stress level. The fitting curves determined by Eq. (3) are shown in Fig. 9. The fitting parameters and regression coefficients of fitting results for every crushed mudstone are shown in Table 3 . The results show that the fitting correlation coefficients are greater than 0.98 , which indicate the Eq. (3) can be used to describe the creep behavior of crushed mudstones in underground mining. 


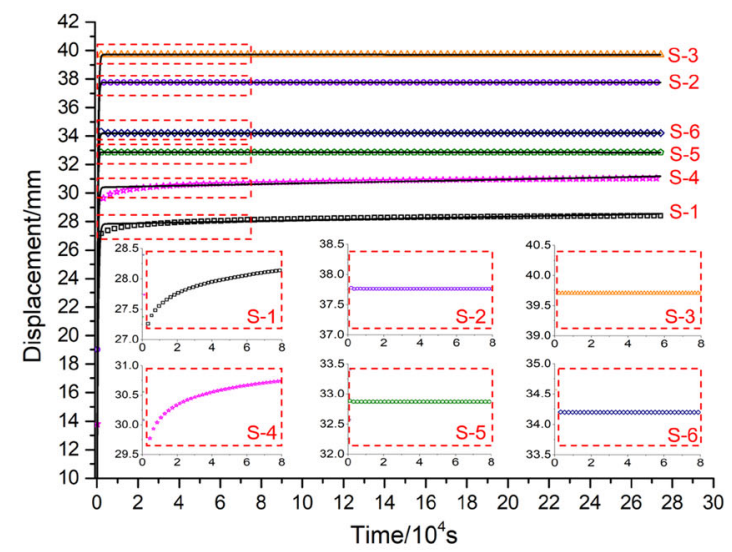

(a) $10 \mathrm{MPa}$

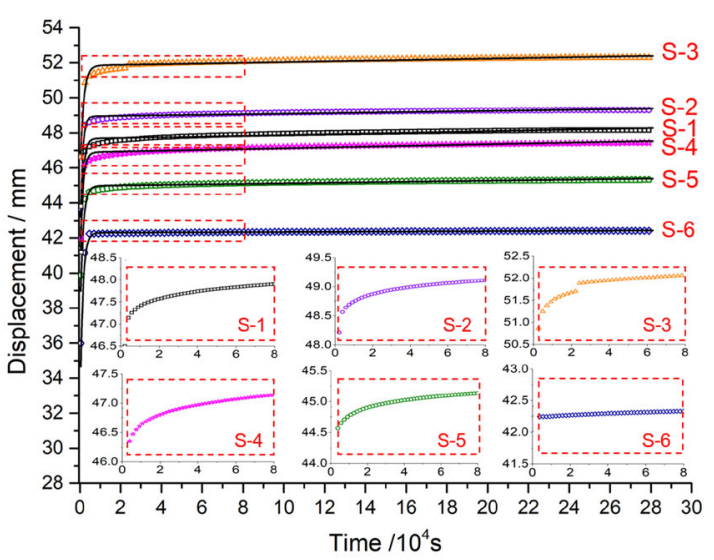

(c) $20 \mathrm{MPa}$

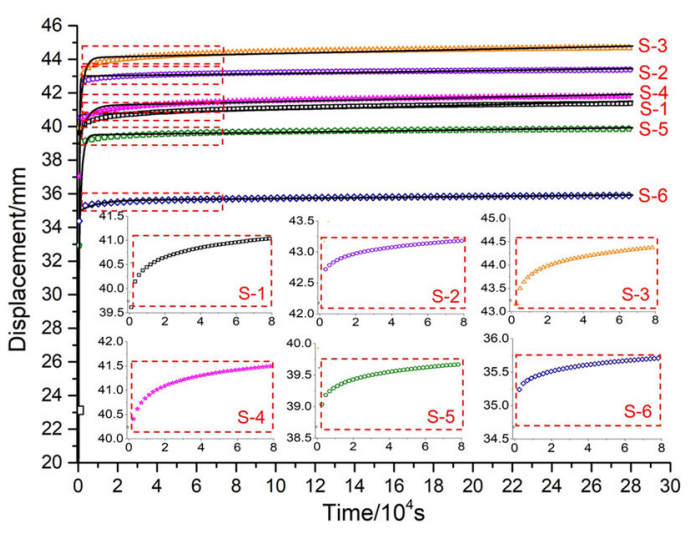

(b) $15 \mathrm{MPa}$

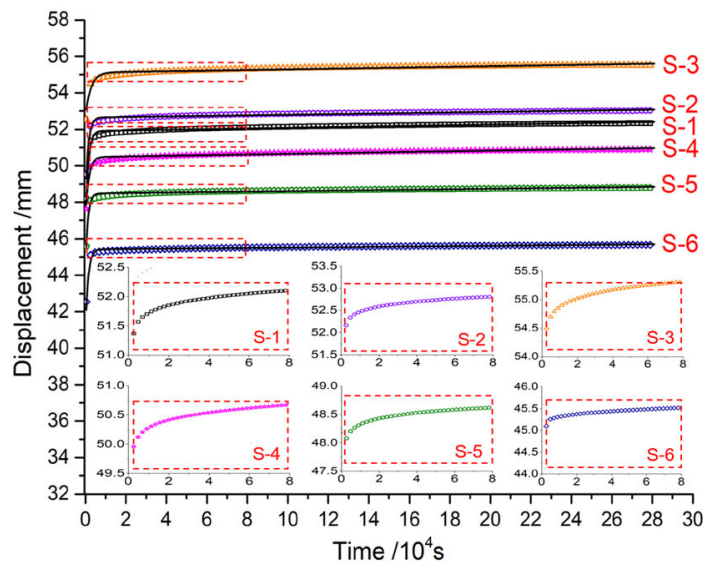

(d) $25 \mathrm{MPa}$

Fig. 9 The creep displacement-time curves of crushed mudstones under different axial stress

\section{Discussion}

It is assumed that there are $N$ contact points between the $J$ th particle and other particles in the crushed rock samples. When the axial loading acts on the crushed rocks, the force and contact area of the $i$ th contact point are $P_{i}, \delta_{i}$ respectively $(i=1,2, \ldots, N)$. As shown in the Fig. 10, taking the contact surface A of $J$ th particle as the study object. Assuming that there are $M$ contact points $(M \leq N)$ on the contact surface A, and the total normal stress $\sigma_{\mathrm{A}}$ and total shear stress $\tau_{\mathrm{A}}$ on the contact surface $\mathrm{A}$ are:

$\sigma_{\mathrm{A}}=\sum_{i=1}^{M} \frac{P_{i}}{\delta_{i}} \cos \alpha_{i}$

$\tau_{\mathrm{A}}=\sum_{i=1}^{M} \frac{P_{i}}{\delta_{i}} \sin \alpha_{i}$

where $\alpha_{i}$ is the angle between the normal of the contact surface $A$ and the direction of the total force applied in the $i$ th contact point.
A slight rotation or slip will take place in response to a resultant force of $\tau_{\mathrm{A}}$. And the total normal stress $\sigma_{\mathrm{A}}$ will produces extrusion effect on $J$ th particles. Under the combined effect of $\sigma_{\mathrm{A}}$ and $\tau_{\mathrm{A}}$, the particle rearrangement, particle crushing, and particle splitting take place in the compaction and creep process of crushed rocks. These processes take place repeatedly in the creep and compaction tests. The crushing behavior is caused by the stress concentration of contact points, which can reduce the original particle size and result in large amounts of fine particles. When the extrusion stress of $i$ th contact point $\sigma_{i}$ is larger than its crushing strength $\sigma_{\mathrm{cr}}$, the crushing behavior will take place. If there are $K_{1}$ contact points crushed, that is:

$\sigma_{i}^{k_{1}} \geq \sigma_{\mathrm{cr}}^{k_{1}} \quad\left(k_{1}=1,2, \ldots, K_{1}\right)$

The splitting behavior mostly results from weak parts in the particles, which form the fractures and separate the crushed rock particle into two parts. It is accompanied with crushing behavior when the extrusion stress of $j$ th contact 
Table 3 Regression coefficients of the fitting curves for the crushed samples under different axial stresses

\begin{tabular}{|c|c|c|c|c|c|}
\hline \multirow[t]{2}{*}{ Samples } & \multirow[t]{2}{*}{ Regression coefficients } & \multicolumn{4}{|c|}{ Axial stress } \\
\hline & & $10 \mathrm{MPa}$ & $15 \mathrm{MPa}$ & $20 \mathrm{MPa}$ & $25 \mathrm{MPa}$ \\
\hline \multirow[t]{4}{*}{ S-1 } & $a$ & 28.416 & 41.392 & 48.168 & 52.333 \\
\hline & $b$ & 1.332 & 1.497 & 2.060 & 1.649 \\
\hline & $c$ & 0.014 & 0.018 & 0.027 & 0.030 \\
\hline & $d$ & 0.034 & 0.039 & 0.031 & 0.034 \\
\hline \multirow[t]{4}{*}{ S-2 } & $a$ & - & 43.40 & 49.297 & 53.016 \\
\hline & $b$ & - & 0.694 & 1.552 & 2.980 \\
\hline & $c$ & - & 0.014 & 0.028 & 0.056 \\
\hline & $d$ & - & 0.045 & 0.030 & 0.035 \\
\hline \multirow[t]{4}{*}{ S-3 } & $a$ & - & 44.677 & 52.275 & 55.508 \\
\hline & $b$ & - & 1.440 & 2.069 & 4.915 \\
\hline & $c$ & - & 0.016 & 0.020 & 0.048 \\
\hline & $d$ & - & 0.035 & 0.024 & 0.026 \\
\hline \multirow[t]{4}{*}{ S-4 } & $a$ & 31.053 & 41.831 & 47.432 & 50.928 \\
\hline & $b$ & 1.412 & 1.438 & 2.187 & 1.433 \\
\hline & $c$ & 0.015 & 0.015 & 0.031 & 0.028 \\
\hline & $d$ & 0.036 & 0.036 & 0.024 & 0.039 \\
\hline \multirow[t]{4}{*}{ S-5 } & $a$ & - & 39.878 & 45.330 & 48.821 \\
\hline & $b$ & - & 0.875 & 1.483 & 1.7234 \\
\hline & $c$ & - & 0.018 & 0.030 & 0.0472 \\
\hline & $d$ & - & 0.0398 & 0.033 & 0.040 \\
\hline \multirow[t]{4}{*}{ S-6 } & $a$ & - & 35.912 & 42.422 & 45.689 \\
\hline & $b$ & - & 0.692 & 0.233 & 2.391 \\
\hline & $c$ & - & 0.014 & 0.011 & 0.081 \\
\hline & $d$ & - & 0.043 & 0.048 & 0.046 \\
\hline
\end{tabular}

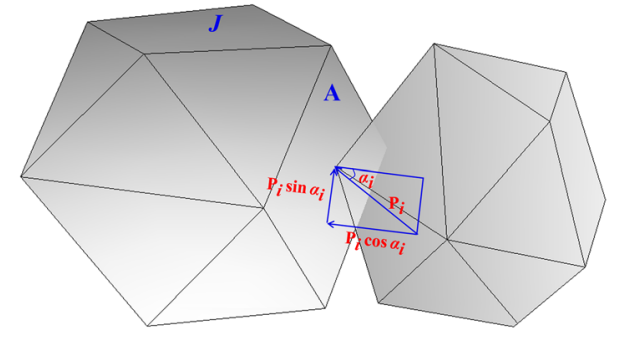

Fig. 10 Force analysis diagram of particles

point $\sigma_{j}$ is larger than the splitting strength $\sigma_{\mathrm{sp}}$. If there are $K_{2}$ contact points splitted, that is:

$\sigma_{j}^{k_{2}} \geq \sigma_{\mathrm{sp}}^{k_{2}} \quad\left(k_{2}=1,2, \ldots, K_{2}\right)$

This creep compaction process is shown in Fig. 11. Figure $11 \mathrm{a}$ is the initial state of crushed rocks before loading. Once the axial stress $p_{1}$ of first loading stage applied, the large voids in crushed rocks are compressed, as shown in Fig. 11b. In the loading stage, the extrusion stress of most particles caused by $p_{1}$ is smaller than the particle crushing strength, the axial deformation of crushed

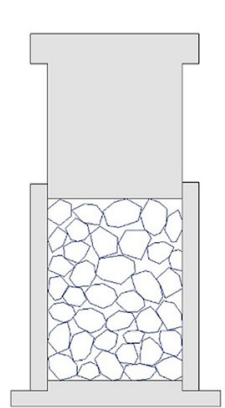

(a)

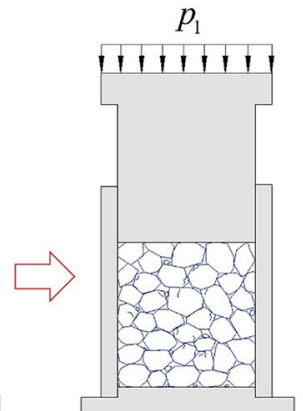

(b)

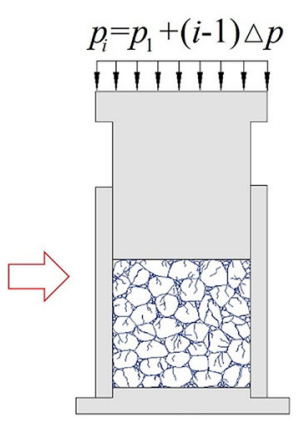

(c)
Fig. 11 The compaction and creep process of crushed mudstones under step loading

mudstones is mainly caused by the large void compression and particles flow without significant particle breakage. As the axial stress increases to $p_{i}$ ( $p_{i}$ is the axial stress of $i$ th loading stage), the extrusion stress of most particles increases to its crushing strength and splitting strength, thus resulting a mass of particle crushing and splitting behavior occurred in samples, which is illustrated in Fig. 11c. The 
cracking behavior will take place extensively as the axial stress continue to increase and large amounts of small particles are formed because of the cracking behavior. The small particles will fill the residual intergranular voids and result in an increase in axial displacement of crushed mudstones.

The heterogeneous decreasing in axial displacement of sample S-3 and S-6 can be explained by the theoretical analysis above. Compared with other samples, there are more larger particles existed in the sample S-3, S-6. When the large particles are enough, the "framework structure" will be formed. Which can improve the compressive strength of crushed mudstones. From the test results, we can know that the extrusion stress $\sigma_{2}$ is smaller than the crushing strength for S-3, S-6 when the axial stress is $15 \mathrm{MPa}$, so the strain increment of $15 \mathrm{MPa}$ is extremely small. As the axial stress increases to $20 \mathrm{MPa}$, the extrusion stress $\sigma_{3}$ increases to crushing strength of S-3, S-6, resulting in an increase in small particles and a large increase in axial displacement.

\section{Conclusions}

This paper presents the results of creep compaction testing program intents to study the compaction and creep behavior of different graded crushed mudstones in underground mining. Based on the analysis of the tested data, the following conclusions have been obtained:

(1) The axial displacement corresponding to each loading stage decreases progressively as the axial loading increases for S-1, S-2, S-4, S-5, but the heterogeneous decrease of S-3, S- 6 are observed at stress level of 15 to $20 \mathrm{MPa}$. Such heterogeneous decreasing behaviors are caused by the higher compressive strength of "framework structure" formed by large particles in crushed rocks, which indicates the larger particles in samples has a significant influence as the reinforcing effect on the compressive behavior of crushed mudstones.

(2) The creep compaction behaviors of crushed rocks are highly dependent on the original grain composition and axial stress applied on the samples. The samples with larger particle size or higher larger particle content are easier to deform at the initial loading stage and exhibit greater stability than smaller particles when the axial stress is less than the bearing capacity of "framework structure". However, when the axial stress is sufficiently high, the influence of grain composition on deformability of crushed mudstones is not distinct after the crushed rock experiences repeated compression.
(3) The axial displacement of crushed mudstones in transient compression stage is quite large and the axial displacement in decay creep is extremely small comparatively. The relationship between axial creep displacement and time can be described by $\varepsilon=a-b e^{(-t-c) / d}$. In the creep tests, the creep behavior prefers to occur in the samples with smaller particles at lower stress level, which is mainly caused by particles flow without significant particle breakage. As the axial stress increases, the singlesized sample with smaller particle size and the wellgraded sample with larger Talbol power exponent $n$ present more unstable under the constant stress. In addition, the filling of the residual intergranular voids by small particles formed by crushing and splitting behavior is the main cause of creep deformation.

Acknowledgements This research was supported by the National Natural Science Foundation of China (Grant No. 51479195), the National Key Research and Development Plan of China (2016YFC0600901), the Special Fund of Basic Research and Operating of China University of Mining and Technology, Beijing (Grant No. 2009QL06), and the State Scholarship Fund of China.

Open Access This article is distributed under the terms of the Creative Commons Attribution 4.0 International License (http://crea tivecommons.org/licenses/by/4.0/), which permits unrestricted use, distribution, and reproduction in any medium, provided you give appropriate credit to the original author(s) and the source, provide a link to the Creative Commons license, and indicate if changes were made.

\section{References}

Berest P, Blum PA, Charpentier JP, Gharbi H, Vales F (2005) Very slow creep tests on rock samples. Int J Rock Mech Min Sci 42:569-576

Fujii Y, Kiyama T, Ishijima Y, Kodama J (1999) Circumferential displacement behavior during creep tests of brittle rocks. Int $\mathbf{J}$ Rock Mech Min Sci 36:323-337

Guo ZB, Wang J, Cao TP, Chen L, Wang J (2016) Research on key parameters of gob-side entry retaining automatically formed by roof cutting and pressure release in thin coal seam mining. J China Univ Ming Technol 5:879-885

Guo ZB, Wang Q, Wang HH, Ma ZM, Yin SY, Hu HL (2018) Broken expand propertities and lateral pressure analysis of mud rock of gangue rib in gob-side entry retaining formed by roof-cutting and pressure-releasing. J China Univ Ming Technol 5:987-994

Hagin PN, Zoback MD (2004) Viscous deformation of unconsolidated sands-part 1: time-dependent deformation, frequency dispersion, and attenuation. Geophysics 69:731-741

He WW, Hajash A, Sparks D (2003) Creep compaction of quartz aggregates: effects of pore-fluid flow-a combined experimental and theoretical study. Am J Sci 303:73-93

He MC, Zhu GL, Guo ZB (2015) Longwall mining cutting cantilever beam theory and 110 mining method in China-the third mining science innovation. Rock Mech Geotech Eng 7:483-492 
He MC, Gao YB, Yang Y, Gong WL (2017) An innovative approach for gob-side entry retaining in thick coal seam longwall mining. Energies 10:1785-1807

Heap MJ, Baud P, Meredith PG (2009a) Influence of temperature on brittle creep in sandstones. Geophys Res Lett 36:L19305

Heap MJ, Baud P, Meredith PG, Bell AF, Main IG (2009b) Timedependent brittle creep in Darley Dale sandstone. J Geophys Res 114:B07203

Hu XL, Sun MJ, Tang HM, Xie N, Guo J (2014) Creep tests of gravelsoil of Majiagou landslide in Three Gorges Reservoir area. Rock Soil Mech 11:3163-3169+3190 (in China)

Karner SL, Chester JS, Chester FM, Kronenberg AK, Hajash JA (2005) Laboratory deformation of granular quartz sand: implications for the burial of clastic rocks. AAPG Bull 89:603-625

Lade PV, Liu CT (1998) Experimental study of drained creep behavior of sand (1998). J Eng Mech 8:912-920

Liang J, Liu HL, Gao YF (2003) Creep mechanism and breakage behaviour of rockfill. Rock Soil Mech 3:479-484

Ma ZG, Gu RX, Huang ZM, Peng G, Zhang L, Ma D (2014) Experimental study on creep behavior of saturated disaggregated sandstone. Int J Rock Mech Min Sci 66:76-83
Scholz CH (1968) Mechanism of creep in brittle rock. J Geophys Res 73:3295-3302

Suiker ASJ, Selig ET, Frenkel R (2005) Static and cyclic tri-axial testing of ballast and subballast. J Geotech Geoenviron Eng 6:771-782

Sun QD, Indraratna B, Nimbalkar S (2015) Deformation and degradation mechanisms of railway ballast under high frequency cyclic loading. J Geotech Geoenviron Eng 1:04015056

Thakur PK, Vinod JS, Indraratna B (2013) Effect of confining pressure and frequency on the deformation of ballast. Géotechnique 9:786-790

Wang YJ, Gao YB, Wang EY, He MC, Yang J (2018) Roof deformation characteristics and preventive techniques using a novel non-pillar mining method of gob-side entry retaining by roof cutting. Energies 11:627

Wichtmann T, Rondón HA, Niemunis A, Triantafyllidis TH, Lizcano A (2009) Prediction of permanent deformations in pavements usinga high-cycle accumulation model. J Geotech Geoenviron Eng 5:728-740

Yang CH, Daemen JK, Yin JH (1999) Experimental investigation of creep behavior of salt rock. Int J Rock Mech Min Sci $36: 233-242$ 